\begin{tabular}{c} 
Volume and Issues Obtainable at Center for Sustainability Research and Consultancy \\
Journal of Business and Social Review in Emerging Economies \\
ISSN: 2519-089X (E): 2519-0326 \\
Volume 6: Issue 2 June 2020 \\
ᄃSRட \\
Journal homepage: $\underline{\text { www.publishing.globalcsrc.org/jbsee }}$ \\
\hline
\end{tabular}

\title{
Scope of Social Work Practice in Childcare Social Welfare Institutions: Policies, Practices and Problems
}

\author{
${ }^{1}$ Muhammad Arshad, ${ }^{2}$ Aliya Khalid, ${ }^{3}$ Syeda Mahnaz Hassan
}

${ }^{1 \& 2}$ Assistant Professor, Department of Social Work, University of the Punjab, Pakistan

${ }^{3}$ Chairperson, Department of Social Work, University of the Punjab, Pakistan, drsyedamahnazhassan@ gmail.com

\section{ARTICLE DETAILS}

\section{History}

Revised format: May 2020

Available Online: June 2020

\section{Keywords}

Residential care services,

Pakistan, destitute children,

childcare institutions

JEL Classification

Q53, Q54

\begin{abstract}
Children deprived of their primary care are among the most vulnerable segments of the society exposed to violence, exploitation, trafficking, discrimination and all other types of abuse. United Nations Convention on the Rights of Children (1989) acknowledges the rights of such children and hold member states responsible for provision of alternative care considering the best interest of the children in accordance with their national laws. United Nations' guideline on alternative care were also adopted by UN General Assembly for effective implementation of international instruments regarding the shelter, protection, development, and rehabilitation of children deprived from their primary care. Pakistan, being a member state and signatory to these UN treaties, is bound to reflect the provisions of these international instruments in the domestic policies and execute the same in true letter and spirit. Evidences prove that if not professionally managed, children living and growing up in institutions face difficulties in learning and developing social skills. In Punjab province, different institutions in public \& private sectors are providing residential services to children deprived of their primary care. However, the performance of these institutions has been questioned repeatedly due to the constantly reported child abuse cases. Present study aims to explore factors responsible for the current state of affairs by getting views of both practitioners and the beneficiaries. Following a qualitative perspective of research, in-depth interviews were conducted using a semi-structured interview guide with management and resident children of childcare institutions. The findings of the study identified multiple policy and administrative issues affecting the working of these institutions and helped in understanding the existing situation of these institutions in Punjab Province. This study will be helpful in determining the needs and issues faced by the case managers as well as the children to serve their best interest.
\end{abstract}

\section{OPEN ACCESS}

(C) 2020 The authors, under a Creative Commons AttributionNonCommercial 4.0

Corresponding author's email address: drsyedamahnazhassan @ gmail.com

Recommended citation: Arshad, M., Khalid, A. and Hassan, S. M. (2020). Scope of Social Work Practice in Childcare Social Welfare Institutions: Policies, Practices and Problems. Journal of Business and Social Review in Emerging Economies, 6(2), 949-957 


\section{Introduction}

Social work as a discipline evolved to deal with "individuals, families, groups, and communities" facing problems. According to Council of Social Work Education, USA (1959), "Social work seeks to enhance the social functioning of individuals, singly and in groups, by activities focused upon their social relationships which constitute the interaction between man and his environment. These activities can be grouped into three functions: restoration of impaired capacity, provision of individual and social resources, and prevention of social dysfunction." It is assumed that like other professions, Social Work has also "problem-solving functions", developed as a value-based profession and continues to grow to meet human needs.

IFSW defines "Social work is a practice-based profession and an academic discipline that promotes social change and development, social cohesion, and the empowerment and liberation of people. Principles of social justice, human rights, collective responsibility, and respect for diversities are central to social work. Underpinned by theories of social work, social sciences, humanities and indigenous knowledge, social work engages people and structures to address life challenges and enhance wellbeing" (Watkins, 2014).

Professional social workers while dealing with psycho-social problems of individuals, groups and communities require knowledge in methods of social work which direct and facilitate social workers in solving problems of different segments of society. These methods are grouped as primary and secondary. Primary methods include "Social Case Work, Social Group Work and Community Organization while Social Research, Social Welfare Administration and Social Action" are included in the secondary group. Primary methods are practiced directly with clients who need the professional services while secondary methods help social workers in practicing primary methods. As a profession, social work is practiced in diverse fields and with different people. Homelessness, family welfare, aged care, education, correctional services, child protection, mental health, migration, disability, health care, and administration are some of the areas where social work as a method is practiced.

Child welfare is an important field where a social worker offer service to "children suffered from abuse, neglect, or other negative treatment on a holistic level, addressing physical, emotional, and environmental concerns". Social worker while working with children make efforts to manage the factors cause threatening situation for children and provide a safe environment and consistent support according to the child's circumstances. Considering the sensitivities and special needs, a child welfare social worker requires building his ability to deal with the situation with an "unbiased perspective, to take a variety of important factors into account, and to choose the best course of action through careful evaluation and planning" (CSWE, 2018).

Family has always been the crucial role player in the lives of children and responsible for shaping and developing their values, skills, socialization, and security. Life without a family is critical and may have serious psycho-social, emotional, and economic implications for children. Science proves that children develop best within a family environment, where they will get all the love and support, they need to survive and thrive (Santrock, 2015). "United Nations' Convention on the Rights of the Child" (1989) a popular international agreement has outlined the civil, political, economic, social and cultural rights of every child. The Convention recognizes that "the child, for the full and harmonious development of his or her personality, should grow up in a family environment, in an atmosphere of happiness, love and understanding".

Sometimes, children remain deprived from their biological family due to poverty, disability, adversity, or misperception. In this case, such child has the right "to be placed within a family type environment - through foster care, kinship care or, when there is no chance of returning to their biological family, adoption" (United Nations, 2010). In this situation, UNCRC (1989) guides state parties that "every child who cannot be looked after by their own family has the right to be looked after properly by people who respect the child's religion, culture, language and other aspects of their life". Browne (2017) identified that "majority of these children have at least one living parent or kin, however, the child is handed over to different institutions owing to a scarcity of resources and more prevalent poverty".

According to Ijzendoorn (2011) "children living and growing up in institutions often have difficulties learning and 
developing social skills as even with the best intentions, skills and knowledge, the staff cannot give more than a fraction of the attention needed to help the child build attachment, to communicate and find comfort".

\section{Literature Review}

Reviewing scholarly literature on residential care for children enable researchers for better understanding of the philosophy of alternative care. The literature reviewed in this study would be valuable to learn about the differences between the different forms of alternative care. Most importantly, the review of the relevant literature enriched the researcher of present study about the merits and demerits of different forms of alternative care. Further, it also helped in understanding the present practices of "Social Work Case Managers" while dealing and managing individual cases as well as the overall management of the RCCI.

Several efforts have been made to highlight the adverse effects of long-term institutional care (Goldfarb, 1945, Bowlby, 1951; Provence \& Lipton 1962). Frank et al. (1969) in their article that explores 100 years of pediatrics child psychiatry research say, "In the long-term institutionalization in early childhood increases the likelihood that impoverished children will grow in psychiatrically impaired and economically unproductive adults". According to Quinton (1987), "residential care is now seen as an unsatisfactory long-term option when children cannot be looked after by their own parents". Altshuler and Poertner (2002) found "youth living in group homes or institutions take more risks have more threats to achievement and have poorer peer influences".

Chamberlain and Reid (1998) report "on the basis of our findings, it is becoming clear that developmentally appropriate, intensive and individualized family focused treatment is both feasible and superior to group care at any point in the developmental trajectory of antisocial gangsters". According to Barth (2002) "there is virtually no evidence to indicate that group care enhances the accomplishments of any of the goals of child welfare services; it is not more safe or better at promoting development, it is not more stable, it does not achieve better long term outcomes and it is not more efficient as the cost is far in excess of other forms of care".

Bush (1980) shared that "the children interviewed did not like living in institutions and their comments included criticism of institution for the absence of some essential qualities of parental care". Colton (1992) identified greater use of inappropriate and ineffective techniques of control by the residential caregivers as compared to foster parents. According to Colton, "children's home was generally found less child oriented than the special foster homes". Researchers Conner, Doerfler, Toscano, Volungis and Steingard (2004) identified "disruptive behavioural, anxiety, psychotic and other disorders (e.g. developmental, personality disorder)" after leaving care. They also found a number of medical and psychological problems including asthma, aggressive behaviours and schizophrenia.

Frensch and Cameron (2002) while identifying the characteristics common to children in care concluded that "children and youth served by residential treatment may exhibit multiple and concurrent problems such as behaviour problems, school problems and troubled relationships as well as repeated and unsuccessful use of services with frequent out-of-home placements and they enter through a number of multiple pathways (e.g. family, physician, Children's Aid Societies, or court referrals)". "Chaotic behaviour, poor impulse control, proneness to harm others, destruction of property, use of physical threats, difficult relations with parents along with heightened states of parentchild conflict to rejection by parents and inappropriate sexual behavior" were also found common problems in children who were placed in care. Moreover, "chronic residential instability, unsatisfactory sleeping arrangements, risky behaviours from staff and the peer group" were among the major issues highlighted.

Roche (2019) reported aggression and tendencies of delinquency and other behavioral problems as salient feature of residential care. A consensus was found on the part of the respondent practitioners that "children in residential care were vulnerable to different problems more complex in nature problems including higher levels of delinquency, bullying and abuse of drugs". Harper \& McLanahan (2004) identified that "the lives of children in residential care are troubled by chronic residential instability, unsatisfactory sleeping arrangements, and difficult family relationships and most are more than likely to come from low income households". 
Frensch, Cameron and Adams (2001) concluded that "researches conducted on residential care lack consensus regarding definition of residential care and the types of treatment provided in such facilities and the role and involvement, if any, of families and community in the treatment process, as reflected in the child welfare discourse". Holland (2009) identified absence of children's views in the literature when he reviewed 44 studies regarding the children in alternative care carried out by Holland (2009) identified that this field of literature tends to neglect children's views. The review of the by Holland also identified the research methods and theoretical orientations used to obtain children's views ranging from large surveys to in-depth creative engagement with small numbers. Stein (2006) asserts that "the literature on residential care is mainly empirically driven and dominated by descriptive studies".

Berridge (2007) suggested that most of the researches around the subject were under-theorized. Winter (2006) argued that "by using sociological models of childhood in research, researches may have more nuanced understanding of children, interconnections between the looked after setting and other social and cultural factors and paying attention to children's capacities and agency". Winter also identified gaps in the studies reviewed by arguing that "research which sought the views of children was often similarly constrained by adult-oriented measures".

Holland (2009) also identified different theoretical or conceptual frameworks used reviewed studies. Among them, phenomenologicaV interpretive was the major conceptual/theoretical framework used along with sociology of childhood/ children's rights. She explored that "theories of participation, resilience, attachment, life-course, ethic of care, child development theory, hope theory, social network theory" have also been used in the research occasionally. She hypothesized that "where researchers deliberately aim to include children's experiences or perspectives in a research design, they may be working within a more explicit theoretical frame-work, as a standpoint or due to the nature of the research questions". Sally recognized that theories mentioned above was the demonstration of a wide range of "epistemological paradigms" being utilized in this body of research.

The scholarly literature reviewed above shows that institutionalized of children residential care service can become damaging if not planned professionally. Reviewing literature on residential care for children helped the researcher in understanding the methods, perspectives and techniques used in the past studies. "Qualitative interviewing standardized measures, survey, observation, ethnography, focus group and multi-modal qualitative design" were among the major methods explored while reviewing the literature. In Pakistan, very few researches were available regarding the alternative for children. Among them, majority of the studies were undertaken at a small scale, focusing on single institution, mostly quantitative in nature and their research designs allowed very little freedom for children's individual experiences to share. Due to their Problematic methodological and theoretical issues, it was very difficult to produce reliable data and to generalize the findings. Further, no study was found discussing the ethical issues while working with the children in institutional care.

\subsection{Children Deprived of Family Care in Pakistan: A Situational Analysis}

Pakistan, located in South Asia, is a home to more than 220 million people and among them, there are over 80 million children. Almost one fourth population of the country (24.3\%) lives below the poverty line (Van, 2020). In this situation, children are among the most vulnerable segments of the society deprived of basic need such as "food, drinking water, education, and health services". In Pakistan, knowledge about child rights, their development needs and protection issues are limited. Various socio-economic \& cultural factors in Pakistan are affecting the survival, development, protection, and participation rights of children. Due to poverty and abandonment, thousands of children are living in institutional care, experiencing social-emotional care altogether different from primary (family) care.

According to a recent research study (Ali, Yildirim, Hussain, \& Vostanis, 2020) "Children in care experience multiple risk factors" in Pakistan. The study also reported "high rates of posttraumatic stress (70.45\%) and common mental health symptoms (43.94\%) within the clinical range, but also high levels of posttraumatic growth". Complaints against the staff of the child care institutions regarding abuse, violence and exploitation against children have been reported in the media invite researchers work in this important field of social work to understand the policies, practices and problems of these residential child care institutions. 
"Children deprived of their family due to any reason including poverty, disability, adversity or misperception has the right to be placed within a family type environment - through foster care, kinship care or, when there is no chance of returning to their biological family, adoption" (UNICEF, 2020). "United Nations Child Rights Convention" (1989) requires the state parties that "every child who cannot be looked after by their own family has the right to be looked after properly by people who respect the child's religion, culture, language and other aspects of their life". According to the statistics of UNICEF (2019), "there are approximately 2.7 million children living in institutional care across the globe presently, and the actual number goes even higher". Besides UN guidelines on alternative care, several states have developed minimum standards of care to mitigate the risk for children to protect their health, safety and wellbeing.

Traditionally, joint family system has been a great source of material and emotional security, education, and vocational training for its members in Pakistan. However, changing dynamics of the society in both rural and urban areas have affected this social institutions and cause failure in providing adequate psycho-social and material support to the child. Modern life associated with urbanization is making unknown and heavy demands on individuals, cumulating difficulties for children in need of alternative care.

State of Children in Pakistan (2015) informed "large numbers of children in Pakistan are living in institutional care and the existing institutions providing alternative care are inadequate, both qualitatively and quantitatively, and lack mechanisms for conducting periodic reviews of placement". The report also indicated serious concerns about the facilities of the institutions and observed that "the standard of such facilities are not up to the mark as majority of these institutions are confining the underprivileged children in an environment that hinders their growth and development". Besides, due to inadequate protection measures including absence of child protection and safeguarding policies, trained \& qualified staff, monitoring \& evaluation mechanism, child abuse cases are reported frequently. Another reason behind this vulnerable situation is the confusion about the mandate to regulate these institutions in Punjab province. Mostly, the residential homes in public sector are administered by the "Department of Social Services (Social Welfare)" worldwide, as this is usually the agency that has responsibility for providing services for children and families and to monitor the execution of relevant policies.

Punjab, being the most populated province of the country, also accommodates a large number of destitute, abandoned, and vulnerable children in residential care. However, in Punjab Province, the task of "child welfare and protection" which has been dealt by the "Social Welfare Department (SWD)" shifted to the "Child Protection \& Welfare Bureau (CPWB)" without proper amendments in the rules of business and administrative arrangements. This has affected the overall situation and ultimately increased the vulnerabilities of these destitute population living in the childcare institutions.

The hierarchy of the Directorate General of Social Welfare and the institutions identifies that department of Social Welfare provide different services to children in need of care including residential facilities. On the other hand, "Child Protection and Welfare Bureau (CPWB)", an autonomous body, established under the "Punjab Destitute and Neglected Children Act 2004" also provide "rescue, protection, rehabilitation, residential care and reintegration services to destitute and neglected children such as beggars, street children, and handicapped" (State of Children in Pakistan, 2015). The residential child protection institutions (CPIs) have been established in Lahore, Gujranwala, Sialkot, Rawalpindi, Faisalabad, Sargodha, Multan, Bahawalpur, and Rahim Yar Khan Districts of Punjab.

Table-1: List of Child Care Institutions in Social Welfare Department, Punjab

\begin{tabular}{|l|c|l|}
\hline \multicolumn{1}{|c|}{$\begin{array}{c}\text { Institution Under Social } \\
\text { Welfare Department }\end{array}$} & No. & \multicolumn{1}{|c|}{ Purpose of the Institutions } \\
\hline Nigebhan Centers & 8 & $\begin{array}{l}\text { "Reintegration of lost, kidnapped and runaway } \\
\text { children" }\end{array}$ \\
\hline Chaman & 1 & $\begin{array}{l}\text { "Trains and rehabilitates (education) } \\
\text { mentally impaired children" }\end{array}$ \\
\hline Children Homes & 11 & $\begin{array}{l}\text { "Provides shelter and education services and } \\
\text { rehabilitation" }\end{array}$ \\
\hline
\end{tabular}




\begin{tabular}{|l|c|l|}
\hline Dar-ul-Falah & 6 & $\begin{array}{l}\text { "Provides skill development training to children } \\
\text { of widowed and divorced women with babies" }\end{array}$ \\
\hline Kashana & 3 & $\begin{array}{l}\text { "Provides residential, educational, vocational and } \\
\text { rehabilitation services to destitute girls" }\end{array}$ \\
\hline
\end{tabular}

\section{Methodology}

Managers of the public sector institutions providing residential care services to children and resident children were among the respondents of the study. Managers of 10 institutions, almost $30 \%$ of the total institutions, were interviewed using a semi-structured interview guide while two focus group discussions were conducted with resident children. The selection of the respondents for interview was made by using purposive sampling technique ensuring representation from every category of the institution. In-depth interviews were conducted to obtain information about the existing services, procedures, case management practices, views of children regarding their living experiences and current standards to ensure quality services to the resident children. Information regarding existence and functioning of monitoring and complaint mechanism was also acquired through interviews and FGDs.

\section{Findings and Analysis}

The data collected through semi-structured interview guide and FGDs was analyzed thematically which is usually taken as "a good approach to research to find out something about people's views, opinions, knowledge, experiences or values from a set of qualitative data" like interview transcripts, social media profiles, or survey responses. After familiarization, coding, reviewing, defining, naming, and writing up themes, the findings of the study have been itemized as below:

\subsection{Governance of Residential Care Institutions for Children}

Majority of the managers shared no legislative framework is available or provided to them for the management of these institution. Due to repealing of the "the Punjab Supervision \& Control of Children Homes Act, 1976" the Punjab Destitute \& Neglected Children Act, 2004, the managers shared their confusion in this regard. No institution reported any individual child protection policy, standard operating procedures or exit policies for children residing in the institutions.

\subsection{Case Management Practices in Residential Care Institutions for Children}

Social Work Case Management is a specialized field of practice in Social Work Profession. Graduates of Social Work are educated theoretically and trained practically to manage the cases professionally. However, due to appointment of professionals from other disciplines in these institutions, the practices of social work case management were not found uniform and according to the standards. Lack of theatrical knowledge and trainings, managers shared challenges in dealing with the cases of resident children.

\subsection{Children's Experiences in Residential Care}

As shared by the respondents, majority of children residing in these institutions were not aware about the purpose of their stay at these institutions and their future. Due to separation from their families or deprivation from primary care, most of the children were reported sad, hopeless, and pessimistic towards their lives. Depression, stress, and apprehensive behavior of resident children was also reported by the respondents. Limited staffing and lack of expertise were reported as a major hurdle in dealing children with anomalous behavior.

\subsection{Existing Standards of Residential Care Institutions for Children}

According to the respondents, minimum standards of care have been designed and shared, however, no mechanism was developed to facilitate the implementation of these standards. Despite few capacity building initiatives in this connection, this has been a grey area mostly. The responses were of the view that instead of borrowing the standards from other societies, efforts should be made to develop standards of care based on indigenous needs and local realities.

\subsection{Monitoring Mechanism in Residential Care Institutions for Children}


The respondents shared about the presence of a conventional mechanism for monitoring of these services, yet, acknowledged its ineffectiveness. There was no concept of management councils or child protection committees in the institution on the part of the respondents.

\subsection{Complaint Mechanism available to Children}

It was also alarming that no formal complaint mechanism was placed in the institution for children to launch their concerns. In most of the cases, resident children were encouraged to share their concerns with the staff, however, no mechanism, policy or procedure was adopted and placed by any institution in this regard.

\section{Conclusion and Recommendations}

Despite of limited resources, Social Welfare Department, Punjab is providing multiple services to different categories of children in need of protection and welfare. However, intervention of some legislative and administrative measures can improve the existing services to serve the best interest of the children in care. Literature reviewed, secondary sources consulted and views of the respondents inform that residential care services for children in Punjab Province lack necessary legal, administrative and policy frameworks and guidelines causing a confusion on the part of stakeholders. Duplication of services, divided mandate and vague rules of business are among the major factors affecting the governance and management of childcare services in the province. Child Protection is a delicate matter and children living in care are among the most vulnerable segments, yet, it is quite worrying to know that no specific criteria are available for employing and engaging managers and support staff in childcare institution. No consideration is given to the experience, expertise, exposure, aptitude, attitude, capacity, personality, and security clearance of the staff and usually it is taken as a routine activity of transfer and posting.

It is also a matter of great concern that no comprehensive certification in child protection is being offered by any educational or training institution in Punjab province. Therefore, there is a scarcity of qualified, skilled, and trained human resources to manage these services in a professional way. Though, department of Social Welfare has made several attempts to develop SOPs for case management, minimum standards and organized a number of capacity building activities, yet, the implementation and follow-up of the same is neglected and needs to be focused. Lack of uniform case management practices, conceptual clarity, knowledge, and skills in dealing with child protection issues, logistic and technical support were among the major issues faced by these institutions as reported in the study. Poor physical infrastructure, insufficient financial allocations and limited number of care staff were also among the major issues of the institutions. Low capacity of the support staff and absence of check and balance system were found as root causes of child rights violation cases in the institution.

Considering the situation discussed above, it is recommended that the concerned authorities should take notice of the existing situation and address all the issues identified and shared in the study. A comprehensive legislation must be drafted and approved by the legislative assembly along with clearly defined rules for implementation. Social Welfare Department Punjab in coordination with academia should plan and initiate certification, diploma courses, degree programs and research and development activities in the field of child protection to develop child protection specialists. A comprehensive, practical and relevant standards of childcare must be conscripted in consultation with all stakeholders, shared and implemented. An independent, authorized monitoring committee/commission must be formulated to monitor these services through regular reporting and surprise visits to check the quality of services. Training of staff of childcare institutions should be carried out regularly and their performance is required to be assessed and evaluated on regular basis.

An independent complaint mechanism should be in placed in every institutions and resident students should be informed and encouraged to report any activity, behavior, gesture which annoy them. Orientation session with resident children regarding their fundamental rights are recommended to educate them about their rights. This will help them learn about the difference between appropriate and inappropriate behavior. Most importantly, a child protection management information system should be developed to consolidate the information regarding children in institutional care, individual plans, timelines, and progress in their rehabilitation. It is anticipated that the recommendations of the study will help in improving childcare service delivery mechanism in Punjab. 


\section{References}

Ali, S. M., Yildirim, M., Hussain, S. A., \& Vostanis, P. (2020). Self-reported mental health traumatic growth among children in Pakistan care homes. Asia Pacific Journal Development, 30(1), 62-76. doi:10.1080/02185385.2019.1710726

Altshuler, S.J., \& Poertner, J. The child health and illness profile-adolescent edition: in group homes or institutions. Child Welfare. 2002 May- Jun;81(3):495-513.

B., LeMare, L., Bakermans-Kranenburg, M. J., Dobrova-Krol, N. A., \& Juffer, F. (2011). Institutional Care: Delayed Development and Resilience. Monographs of the Society for Research in Child Development, 76(4), 8-30.

Berridge, D., Biehal, N., \& Henry, L. (2012). Living in children's residential

homes. London: Department

problems and postof Social Work and Education.

Bowlby, J. (1944). Forty-four juvenile thieves. International Journal of Psychoanalysis, 25,

19-53.

Browne, E. (2017). Children in care institutions. K4D Helpdesk Report. Brighton, UK: Institute of Development Studies

Bush, M. (1980). Institutions for dependent and neglected children: Therapeutic option of

choice or last resort? American Journal of Orthopsychiatry, 50(2), 239-255.

Chamberlain, P., \& Reid, J. B. (1998). Comparison of two community alternatives to incarceration for chronic juvenile offenders. Journal of Consulting and Clinical Psychology, 66(4), 624-633.

Children in alternative care. (2019, January 27). Retrieved July 31, 2020, from https://data.unicef.org/topic/childprotection/children-alternative-care/

Colton, M. J. (1992). Carers of children: A comparative study of the practices of residential and foster carers. Children \& Society, 6(1), 25-37.

Frank D.A., Klass, P.E.,Earls, F., \& Eisenberg, L. (1996). Infants and young children in orphanages: one view from pediatrics and child psychiatry. Pediatrics.97(4):569-578.

Frankel, A. J., \& Gelman, S. (2016). Case management: An introduction to concepts and skills.

Frensch, K. M., \& Cameron, G. (2002). Treatment of choice or a last resort? A review of residential mental health placements for children and youth. Child \& Youth Care Forum, 31(5), 307-339.

Goldfarb, W. (1945). Effects of psychological deprivation in infancy and subsequent stimulation.

American Journal of Psychiatry, 102, 18-33.

Goodwin, D., Pope, C., Mort, M., \& Smith, A.C. (2003). Ethics and Ethnography: An $\quad$ Experiential Account. Qualitative Health Research, 13, 567 - 577.

Gupta, I. N. (2019, March 13). Institutional Care: Impacts on Children. Retrieved July 30, 2020,

From https://yourstory.com/mystory/institutional-care-impacts-on-children-i38vhdff2s

Harper, C.C., \& Mclanahan, S. (2004). Father Absence and Youth Incarceration. Father Absence and Youth Incarceration. Journal of Research on Adolescence, 14(3):369-397

Ignatieff, M., (2000). The rights revolution. Toronto: House of Anansi Press Limited)

IJzendoorn, M. H., Palacios, J., Sonuga-Barke, E. J., Gunnar, M. R., Vorria, P., McCall, R.

Johnson, L. C., \& Yanca, S. J. (2011). Social work practice: A generalist approach. Boston, Bacon

Kirst-Ashman, K. K., \& Hull, G. H. (2015). Understanding generalist practice.

Mehnaz, A. (2011). State of children in Pakistan--confronting reality. JPMA. The Journal of

the Pakistan Medical Association, 61(6), 518-519.

Parmar, A. (1990). Team Building, Inter-agency Team Development and Social Work Practice. The British Journal of Social Work. doi:10.1093/oxfordjournals.bjsw.a055676

Provence, S., \& Lipton, R. C. (1962). Infants reared in institutions. New York: International Universities Press.

Qin, D. (2016). Positionality in Nancy Naples (eds.) Oxford: The Wiley-Blackwell Encyclopedia of Gender and Sexuality Studies.

Quinton, D. (1987). The consequences of care: Adult outcomes from institutional rearing. Therapeutic Education, 5(2), 18-29.

Roche, S. (2019). A scoping review of children's experiences of residential care settings in Children and Youth Services Review, 105.

Maladjustment \& the global South. 
Ryan, GW. \& Bernard, HR. (2000). "Data management and analysis methods." In NK Denzin \& Santrock, J. W. (2015). Child development. Boston: McGraw-Hill.

Sarantakos, S. (2013). Social research. Basingstoke: Palgrave Macmillan.

Stein, M.(2006). Young people aging out of care: The poverty of theory. Children and Youth Services Review, Elsevier, vol. 28(4), pages 422-434.

UNICEF. (2017). Situation Analysis of Children in Pakistan. Islamabad: UNICEF.

UNICEF.(2020). North Maccedonia. Retrieved July 29, 2020, from UNICEF global: https://www.unicef.org/northmacedonia/children-deprived-family-environment

United Nations. (2010). Guidelines for the Alternative Care of Children. Guidelines for the Alternative Care of Children. United Nations General Assembly.

Van IJzendoorn, M. H., Palacios, J., Sonuga-Barke, E. J., Gunnar, M. R., Vorria, P., McCall, $\quad$ R. B., LeMare, L., Bakermans-Kranenburg, M. J., Dobrova-Krol, N. A., \& Juffer, F.

Winter, K.(2006). Widening our knowledge concerning young looked after children. The case for research using sociological models of childhood. Child and Family Social Work, 11 (1)(1), 55-64. 